\title{
Effects of tobacco smoking on findings in chest computed tomography among asbestos-exposed workers
}

\author{
T. Vehmas*, L. Kivisaari\#, M.S. Huuskonen*, M.S. Jaakkola*
}

\begin{abstract}
Effects of tobacco smoking on findings in chest computed tomography among asbestosexposed workers. T. Vehmas, L. Kivisaari, M.S. Huuskonen, M.S. Jaakkola. (C)ERS Journals Ltd 2003.
\end{abstract}

ABSTRACT: This study examined the effects of smoking on the findings in chest computed tomography $(C T)$ in 587 asbestos-exposed construction workers (11 females, 576 males, mean age 62 yrs; 18 never-smokers, 406 exsmokers and 163 current smokers). The workers were imaged with spiral CT and high-resolution CT. A total of 13 radiological signs were scored by three radiologists independently. The workers' medical data, smoking habits and occupational exposures were collected at an interview. The effects of smoking status and smoked pack-yrs $(0-87.5)$ on the CT signs were studied using multivariate analysis adjusted for confounding factors.

Smoking increased all emphysema signs and contributed to bronchial wall thickening. Smoking was negatively associated with curvilinear and septal lines as well as with parenchymal bands. In persons who had smoked $<\mathbf{1 0}$ pack-yrs, smoking was positively related to paraseptal emphysema and to bronchial wall thickening and negatively related to septal lines, subpleural nodules and honeycombing.

Smoking was related to several abnormal computed tomography signs even among those with relatively small exposure. Computed tomography can detect changes due to smoking at an early stage.

Eur Respir J 2003; 21: 866-871.

In developed countries, as a whole, tobacco is responsible for $24 \%$ of all male and $7 \%$ of all female deaths. These figures increase to $>40 \%$ for males in some countries of Central and Eastern Europe and to $17 \%$ in females in the USA [1]. The average loss of life of smokers is 8 yrs [1]. Smoking is known to cause chronic lung diseases, especially chronic obstructive pulmonary disease, lung cancer and cardiovascular diseases [2]. The prevalence of smoking is still increasing in many parts of the world. Early detection of smoking-induced lung injury would be useful for secondary prevention of smoking related diseases, since awareness of early deleterious effects may promote smoking cessation before a more advanced disease is developed. Computed tomography (CT) may detect parenchymal lung abnormalities in symptom-free smokers with normal findings in chest radiographies and pulmonary function tests [3]. It would be interesting to know whether even relatively small cumulative exposure to smoking (i.e. 1-10 pack-yrs) causes morphological damage in lungs that could be detected with the CT imaging technique. Findings of structural lung changes related to minor exposure to tobacco smoke raises the question of whether such changes could also be caused by exposure to environmental tobacco smoke (ETS).

Smoking is likely to be common among patients with respiratory symptoms who are admitted for chest highresolution computed tomography (HRCT). The diagnosis in HRCT is based on the interpretation of several nonspecific signs. It is thus important to recognise the changes that are due to smoking so that they can be taken into consideration when interpreting $\mathrm{CT}$ signs caused by other factors.

To study the effects of personal smoking and smoked pack-yrs on findings in CT and HRCT 13 separate lung parenchymal findings were assessed in elderly construction workers.
*Finnish Institute of Occupational Health and ${ }^{\#}$ Dept of Radiology, Helsinki University Central Hospital, Helsinki, Finland.

Correspondence: M.S. Jaakkola

Finnish Institute of Occupational Health

Topeliuksenkatu 41 a A

FIN-00250 Helsinki

Finland

Fax: 358947472423

E-mail: maritta.jaakkola@occuphealth.fi

Keywords: Emphysema

fibrosis

lung

radiograph computed

smoking

tomography

Received: April 92002

Accepted after revision: December 262002

\section{Materials and methods}

\section{Study design and population}

A total of 602 construction workers with an asbestosrelated occupational disease ( 85 with asbestosis and 601 with bilateral pleural plaques) were interviewed and imaged with spiral CT and with HRCT in a cross-sectional study. The primary objective of this was the screening for lung cancerand asbestos-related early lung changes $[4,5]$. Smoking data and the assessment of relevant $\mathrm{CT}$ and HRCT findings were available for 587 workers (11 females and 576 males), aged $38-80 \mathrm{yrs}$ (mean $62 \mathrm{yrs}$ ). The characteristics of the study subjects are given in table 1 . The study was approved by the local ethics committee. The informed consent of the patients was asked before they were interviewed and imaged.

\section{Computed tomography technique}

A Picker PQ 2000 scanner (Picker International, Cleveland, USA) was used. The thorax of all study subjects was imaged without enhancement in supine position and with full inspiration using the spiral mode $(10 \mathrm{~mm}$ slices, pitch 1.5 , $140 \mathrm{kV}, 125 \mathrm{~mA}$ ), and in prone position with four to seven sharp algorithm inspiratory HRCT cuts $(1.5 \mathrm{~mm}$ slices, $130 \mathrm{kV}, 200 \mathrm{~mA}$ ). The basic protocol included four slices from the level of carina to the lung bases and extra slices up to a possible seven were imaged in unclear cases. Early on in the study it was realised that extra slices were useful and subsequently seven slices were routinely imaged. In total $\sim 70 \%$ of the study population were imaged with seven slices. 
Table 1.-Characteristics of the study subjects according to tobacco exposure status

\begin{tabular}{lccc}
\hline Characteristic & Never-smokers & Exsmokers & $\begin{array}{c}\text { Current } \\
\text { smokers }\end{array}$ \\
\hline Subjects n & 18 & 406 & 163 \\
Age yrs & $64 \pm 7.5$ & $63 \pm 7.1$ & $60 \pm 7.3$ \\
Pack-yrs & 0 & $22 \pm 14$ & $31 \pm 16$ \\
Asbestos exposure yrs & $27 \pm 9.4$ & $26 \pm 9.7$ & $24 \pm 9.9$ \\
Weight kg & $80 \pm 13$ & $84 \pm 12$ & $78 \pm 14$ \\
Height cm & $173 \pm 8.1$ & $174 \pm 6.6$ & $174 \pm 6.8$ \\
C-reactive protein & $11 \pm 2.5$ & $11 \pm 5.9$ & $11 \pm 5.5$ \\
Mucous production $(0,1)$ & $6(33)$ & $147(36)$ & $100(61)$ \\
Dyspnoea (0-3) & $0.88 \pm 0.81$ & $0.92 \pm 0.94$ & $1.1 \pm 0.91$ \\
Prolonged cough $(0,1)$ & $6(33)$ & $101(25)$ & $89(54)$ \\
\hline
\end{tabular}

Data are presented as mean \pm SD or as $\mathrm{n}(\%)$ for Binary variables (mucus production and prolonged cough), unless otherwise stated.

All images were printed as hard copies with a window width of $1,000 \mathrm{HU}$ and a window level of $-700 \mathrm{HU}$.

\section{Image analysis}

The CT images were evaluated with structured forms independently by three experienced radiologists. The radiologists were blinded to all clinical and smoking data. The 13 radiological signs were subjectively assessed and are shown in Appendix 1.

Findings on both sides were recorded separately. A radiologist's score for both sides was averaged and the mean scores by all three radiologists were used as the outcome in the analyses. The radiologists' intraclass correlation coefficients for the classification of several of these signs have been published previously [5]. Interobserver agreement calculated by quadratic-weighted kappa varied between 0.20 (subpleural nodules) and 0.61 (subpleural curvilinear opacities), while intraobserver agreement was better, from 0.23 (subpleural nodules) to 0.80 (honeycombing).

\section{Exposure assessment}

Information on lifetime smoking habits was obtained in an interview. Never-smokers were defined as persons who had never smoked regularly, i.e. had smoked $<1$ cigarette $\cdot$ day $^{-1}$ for

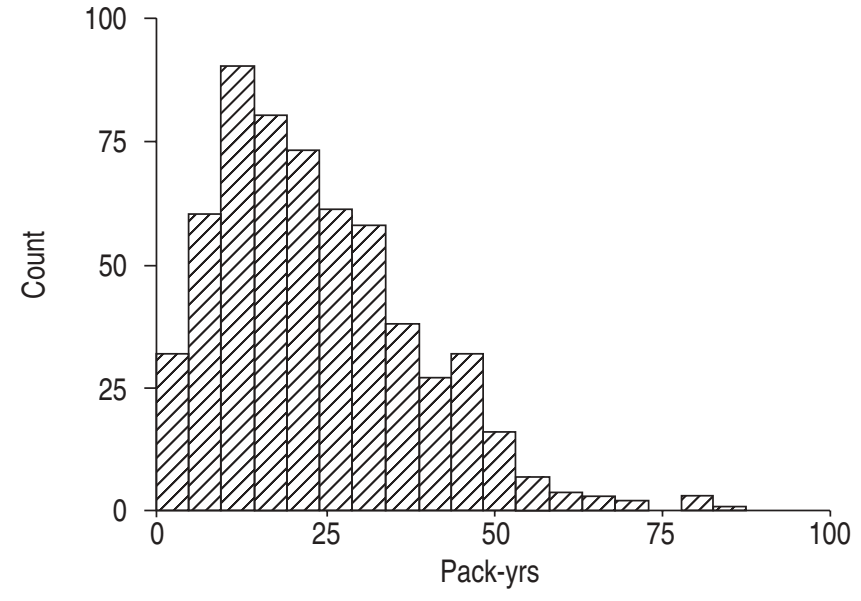

Fig. 1.- Histogram showing the frequency distribution of pack-yrs.

1 yr. Exsmokers were regular smokers who had ceased smoking at least 6 months prior to the CT scanning, and current smokers were regular smokers who were still smoking (or had stopped $<6$ months ago). This grouping is referred to as the smoking status. There were 18 never-smokers, 406 exsmokers and 163 current smokers. Cumulative exposure in pack-yrs (fig. 1) ranged from 0-87.5, with the mean of 23.7. One pack contained 20 cigarettes.

\section{Covariates}

The workers were divided into six occupational groups (engineers, electricians, carpenters, plumbers, insulators and other construction workers) based on their main occupation as reported at their interview. The length of their asbestos exposure was calculated, this varied from 2-48 yrs, with 26 yrs being the average. Occupational grouping, the length of asbestos exposure and the patients' age were all adjusted in the multivariate analyses. All this information was available for 583 persons.

\section{Statistical methods}

The mean scores of radiological findings were computed for different smoking categories and for categories of pack-yrs

Table 2.-Unadjusted mean scores of high-resolution computed tomography (HRCT) findings in categories of smoking according to pack-yrs

\begin{tabular}{|c|c|c|c|c|c|c|c|c|}
\hline \multirow[t]{2}{*}{ HRCT finding } & \multirow{2}{*}{$\begin{array}{c}\text { Never-smokers } \\
0\end{array}$} & \multicolumn{4}{|c|}{ Exsmokers } & \multicolumn{3}{|c|}{ Current smokers } \\
\hline & & $\leqslant 5$ & $>5-10$ & $>10-25$ & $>25$ & $\leqslant 10$ & $>10-25$ & $>25$ \\
\hline Subjects $n$ & 18 & 21 & 56 & 190 & 139 & 14 & 52 & 97 \\
\hline Sub. dependent opacity ${ }^{\#}$ & 0.13 & 0.17 & 0.16 & 0.18 & 0.14 & 0.17 & 0.14 & 0.14 \\
\hline Sub. curvilinear opacity & 0.50 & 0.58 & 0.32 & 0.40 & 0.27 & 0.39 & 0.23 & 0.16 \\
\hline Sub. septal lines & 0.96 & 0.74 & 0.60 & 0.59 & 0.70 & 0.51 & 0.49 & 0.67 \\
\hline Parenchymal bands & 0.55 & 0.49 & 0.28 & 0.39 & 0.41 & 0.60 & 0.43 & 0.53 \\
\hline Sub. nodules & 0.36 & 0.25 & 0.17 & 0.24 & 0.24 & 0.15 & 0.18 & 0.20 \\
\hline Honeycombing & 0.06 & 0.02 & 0.00 & 0.05 & 0.03 & 0.00 & 0.10 & 0.10 \\
\hline Ground-glass opacity & 0.03 & 0.06 & 0.03 & 0.05 & 0.11 & 0.07 & 0.12 & 0.10 \\
\hline Centrilobular emphysema & 0.06 & 0.15 & 0.11 & 0.12 & 0.50 & 0.11 & 0.43 & 0.66 \\
\hline Paraseptal emphysema & 0.00 & 0.02 & 0.02 & 0.08 & 0.30 & 0.10 & 0.27 & 0.40 \\
\hline Panlobular emphysema & 0.06 & 0.22 & 0.11 & 0.13 & 0.40 & 0.23 & 0.25 & 0.33 \\
\hline Bullae & 0.08 & 0.04 & 0.04 & 0.05 & 0.23 & 0.04 & 0.22 & 0.22 \\
\hline Bronchial wall thickness ${ }^{\#}$ & 0.13 & 0.36 & 0.24 & 0.27 & 0.36 & 0.30 & 0.33 & 0.41 \\
\hline Bronchiectasis $^{\#}$ & 0.14 & 0.16 & 0.12 & 0.14 & 0.16 & 0.19 & 0.13 & 0.17 \\
\hline
\end{tabular}

Findings were scored from 0-5 unless otherwise indicated. Sub.: subpleural. ${ }^{\#}$ : scored from 0-3. 
$(0-5,>5-10,>10-25,>25)$. Analysis of covariance was used to study the relations between smoking and the radiological findings. It was studied whether logarithmic transformation of the scores would promote the linear fit of the models; however, this was not found. Therefore, this procedure was not applied as the interpretation of untransformed coefficients is more clinically meaningful. Each model used the score of the radiological finding of interest as the outcome. For each outcome, two models were formed; one including the smoking status as an indicator variable, and the other including the number of pack-yrs as the exposure variable. The effect estimates of pack-yrs were of similar magnitude in current smokers and exsmokers and therefore these groups were combined in the final analyses of pack-yrs. Age, occupational group and the duration of asbestos exposure were included as potential confounders in each model. To study the effects of relatively minor cumulative exposure to tobacco smoke on HRCT findings, a subgroup analysis of workers with a smoking history of $0-10$ pack-yrs $(n=108$ with all covariate information available, 5.6 pack-yrs on average) was performed. Statistical procedures similar to the ones described above were carried out on this group.

\section{Results}

The mean scores of the radiological findings according to the categories of smoking exposure are summarised in table 2. The regression coefficients and their $95 \%$ confidence intervals from the multivariate analyses are presented in tables 3 and 4.

All types of emphysema were strongly related to smoking, the effects of current smoking being stronger. The following relations were detected: 1) centrilobular emphysema, positive association with smoking status $(\mathrm{p}<0.001)$ and pack-yrs $(\mathrm{p}<0.001) ; 2)$ paraseptal emphysema, positive association with smoking status $(\mathrm{p}<0.001)$ and pack-yrs $(\mathrm{p}<0.001)$; 3$)$ panlobular emphysema, current smokers had higher scores than nonsmokers $(\mathrm{p}=0.057)$ and there was also a positive association with pack-yrs $(\mathrm{p}=0.001)$; 4$)$ bullae, positive association with smoking status $(\mathrm{p}=0.041)$ and with pack-yrs $(\mathrm{p}=0.001)$; and 5) bronchial wall thickness was positively related to smoking status $(\mathrm{p}=0.001)$ and to pack-yrs in both current and exsmokers $(\mathrm{p}=0.001)$.

Subpleural curvilinear lines were inversely related to smoking status $(\mathrm{p}=0.003)$ and to smoked pack-yrs $(\mathrm{p}=0.001)$. Subpleural septal lines decreased both in exsmokers $(\mathrm{p}=0.039)$ and current smokers $(\mathrm{p}=0.045)$. Parenchymal bands were less frequent among current and exsmokers than among nonsmokers $(p=0.033)$. Ground-glass opacities had a marginal positive association ( $\mathrm{p}=0.094)$ with pack-yrs in exsmokers.

Analyses among the subgroup of persons who had smoked $\leqslant 10$ pack-yrs $(n=108)$ were performed to evaluate the potential effects of minor cumulative smoke exposure. Paraseptal emphysema $(p=0.038)$ and bronchial wall thickening $(p=0.018)$ were related positively to smoking. There were also negative relations between smoking and HRCT findings in this subgroup. It was observed that both subpleural septal lines $(\mathrm{p}=0.034)$ and subpleural nodules $(\mathrm{p}=0.050)$ decreased with increasing packyrs. Honeycombing was more frequent among never-smokers than among smokers $(\mathrm{p}=0.076)$. Honeycombing also showed a negative relation with pack-yrs $(\mathrm{p}=0.054)$.

\section{Discussion}

To study the potential effects of smoking on CT findings, CT scans were investigated and information on smoking habits obtained in an interview from 587 asbestos-exposed workers. The identification of such effects is important for
Table 3.-Comparison of radiological findings according to the smoking status

\begin{tabular}{|c|c|c|c|c|}
\hline \multirow[t]{2}{*}{ HRCT finding } & \multirow[t]{2}{*}{ B } & \multicolumn{2}{|c|}{$95 \% \mathrm{CL}$} & \multirow[t]{2}{*}{ p-value } \\
\hline & & Lower & Upper & \\
\hline \multicolumn{5}{|c|}{ Sub. dependent opacity } \\
\hline Exsmokers & 0.046 & -0.097 & 0.189 & 0.529 \\
\hline Current smokers & 0.026 & -0.122 & 0.174 & 0.732 \\
\hline \multicolumn{5}{|c|}{ Sub. curvilinear opacity } \\
\hline Exsmokers & -0.137 & -0.381 & 0.106 & 0.268 \\
\hline Current smokers & -0.289 & -0.540 & -0.037 & 0.025 \\
\hline \multicolumn{5}{|l|}{ Sub. septal lines } \\
\hline Exsmokers & -0.287 & -0.559 & -0.015 & 0.039 \\
\hline Current smokers & -0.288 & -0.569 & -0.007 & 0.045 \\
\hline \multicolumn{5}{|l|}{ Parenchymal bands } \\
\hline Exsmokers & -0.132 & -0.366 & 0.102 & 0.267 \\
\hline Current smokers & -0.016 & -0.257 & 0.226 & 0.899 \\
\hline \multicolumn{5}{|l|}{ Sub. nodules } \\
\hline Exsmokers & -0.118 & -0.289 & 0.054 & 0.179 \\
\hline Current smokers & -0.146 & -0.323 & 0.032 & 0.107 \\
\hline \multicolumn{5}{|l|}{ Honeycombing } \\
\hline Exsmokers & -0.004 & -0.120 & 0.113 & 0.950 \\
\hline Current smokers & 0.044 & -0.076 & 0.165 & 0.470 \\
\hline \multicolumn{5}{|l|}{ Ground-glass opacity } \\
\hline Exsmokers & 0.044 & -0.063 & 0.152 & 0.416 \\
\hline Current smokers & 0.083 & -0.027 & 0.194 & 0.139 \\
\hline \multicolumn{5}{|c|}{ Centrilobular emphysema } \\
\hline Exsmokers & 0.218 & -0.097 & 0.534 & 0.175 \\
\hline Current smokers & 0.546 & 0.220 & 0.872 & 0.001 \\
\hline \multicolumn{5}{|c|}{ Paraseptal emphysema } \\
\hline Exsmokers & 0.173 & -0.078 & 0.424 & 0.175 \\
\hline Current smokers & 0.370 & 0.111 & 0.629 & 0.005 \\
\hline \multicolumn{5}{|c|}{ Panlobular emphysema } \\
\hline Exsmokers & 0.191 & -0.084 & 0.467 & 0.173 \\
\hline Current smokers & 0.277 & -0.079 & 0.562 & 0.057 \\
\hline \multicolumn{5}{|l|}{ Bullae } \\
\hline Exsmokers & 0.051 & -0.158 & 0.260 & 0.630 \\
\hline Current smokers & 0.153 & 0.165 & 0.369 & 0.165 \\
\hline \multicolumn{5}{|c|}{ Bronchial wall thickness } \\
\hline Exsmokers & 0.182 & 0.023 & 0.342 & 0.025 \\
\hline Current smokers & 0.266 & 0.101 & 0.430 & 0.002 \\
\hline \multicolumn{5}{|l|}{ Bronchiectasis } \\
\hline Exsmokers & 0.015 & -0.117 & 0.148 & 0.820 \\
\hline Current smokers & 0.031 & -0.105 & 0.168 & 0.653 \\
\hline
\end{tabular}

B: regression coefficients; CL: confidence limits from analyses of covariance; HRCT: high-resolution computed tomography; Sub.: subpleural; Never-smokers form the reference group. A positive B indicates a larger score of the exposure group when compared with never-smokers, and a negative B a smaller score.

differential diagnostics of CT findings and may be useful for the early detection of smoking-induced lung injury and consequently for the secondary prevention of such diseases.

The study population consisted of construction workers with an asbestos-related occupational disease. Therefore, the results cannot be extrapolated directly to the general population, but this occupational group is of special interest for two reasons: 1) this group of people may be at an increased risk of smoking-induced diseases, since persons exposed to asbestos are more likely to be susceptible to the adverse effects of smoking, as has been shown in the case of lung cancer [6]; and 2) workers exposed to asbestos (especially those with pleural plaques) are screened radiologically in many countries [7-9] and smoking-related CT findings may thus be a major differential diagnostic problem.

The study had a large sample of subjects with CT scans. The scoring was based on a subjective scale following the guidelines, described in the image analysis section, rather than 
Table 4. - Effect of pack-yrs on the radiological findings

\begin{tabular}{lcccc}
\hline HRCT finding & \multirow{2}{*}{$\mathrm{B}$} & \multicolumn{2}{c}{$95 \%$ CL } & \multirow{2}{*}{ p-value } \\
\cline { 3 - 4 } & & \multicolumn{2}{c}{ Lower } & Upper \\
& & & \\
Sub. dependent opacity & -0.000263 & -0.00193 & 0.00140 & 0.757 \\
Sub. curvilinear opacity & -0.00469 & -0.00752 & -0.00187 & 0.001 \\
Sub. septal lines & -0.000178 & -0.00333 & 0.00298 & 0.912 \\
Parenchymal bands & 0.000799 & -0.00193 & 0.00353 & 0.565 \\
Sub. nodules & -0.00150 & -0.00349 & 0.000489 & 0.139 \\
Honeycombing & 0.000104 & -0.00125 & 0.00146 & 0.880 \\
Ground-glass opacity & 0.00106 & -0.000181 & 0.00231 & 0.094 \\
Centrilobular emphysema & 0.0126 & 0.00903 & 0.0163 & 0.000 \\
Paraseptal emphysema & 0.00783 & 0.00495 & 0.0107 & 0.000 \\
Panlobular emphysema & 0.00546 & 0.00228 & 0.00865 & 0.001 \\
Bullae & 0.00415 & 0.00174 & 0.00657 & 0.001 \\
Bronchial wall thickness ${ }^{\#}$ & 0.00302 & 0.00117 & 0.00487 & 0.001 \\
Bronchiectasis ${ }^{*}$ & -0.000105 & -0.00164 & 0.00143 & 0.893 \\
\hline
\end{tabular}

Findings were scored from 0-5 unless otherwise indicated. B: regression coefficients; CL: confidence limits from analyses of covariance; HRCT: high-resolution computed tomography; Sub.: subpleural. ${ }^{\#}$ : scored from $0-3$. B represents the change in mean score per 1 pack-yr.

on exact measurements, which were not technically possible. However, the assessment was similar to that which takes place in clinical practice. All three radiologists had several years of experience in analysing CT scans (Professor of radiology at the Helsinki University Hospital, former head radiologist at the Finnish Institute of Occupational Health $(\mathrm{FIOH})$ and the current head of radiology at $\mathrm{FIOH}$ ). Intraobserver assessment was reliable in the present study and interobserver assessment was also good for most of the signs. Averaging the score given by several observers increased the accuracy of the assessment [10]. Scoring all findings with a similar scale (e.g. all from $0-5)$ might have been preferable to keep the regression coefficients comparable.

The basic protocol included four HRCT slices and allowed for more in unclear cases to keep the radiation burden to the study subjects as low as possible. Early on in the study, when it was realised that extra slices were useful, seven slices were routinely imaged. During the study $\sim 70 \%$ of the study population were imaged with seven slices. No standardised reference images are available for grading asbestos exposureor smoking-related HRCT findings. The current manuscript is part of a project aimed at developing guidelines for such grading and is participating in an international effort to standardise such HRCT analysis. There seems to be relatively few studies and no consensus on the optimal window parameters in HRCT. The window setting used in this study (window level -700 $\mathrm{HU}$ and window width 1,000 HU) is recommended for general diagnostics of lung diseases [11], while a wide window might improve the visualisation of pleuroparenchymal abnormalities (adhesions, pleuroparenchymal lines and visceral pleural fibrosis). All patients were imaged in a similar way irrespective of their smoking (or asbestos exposure) status, so the selection of the window settings or any other technical parameter did not introduce any systematic error in the comparisons presented. In addition, the graders were unaware of the exposure status of the subjects, eliminating observer bias due to awareness of exposure.

The interviewer inquiring about smoking history was unaware of the CT findings of the subjects at the time of the interview. Although there were only 18 never-smokers in the present study population, there was wide variability in pack-yrs, extending up to 87.5 pack-yrs. The multivariate analyses adjusted for the subjects' main occupation, age and length of their asbestos exposure to minimise their confounding effect. Respiratory symptoms or coexisting diseases were not adjusted for. Smoking is known to be a risk factor for a variety of respiratory symptoms and diseases, therefore removing such persons from the material would have biased the study and most likely diluted the smoking effect. As table 1 shows, current smokers were found to have more symptoms related to chronic bronchitis which was consistent with the radiological findings. The mean $\mathrm{C}$-reactive protein value did not differ between the exposure groups indicating that the results were not biased by respiratory infections.

There are only a few previous studies on the effects of smoking on HRCT findings. REMY-JARDIN et al. [3] found several positive associations between the smoking status and HRCT findings (amount of parenchymal micronodules, ground-glass opacities, emphysema and dependent attenuation) in a population of asymptomatic smokers. Emphysema, ground-glass opacities, parenchymal micronodules, and bronchial wall thickening characterised current smokers in a study by MASTORA et al. [12]. In the present study, smoking was associated with increased occurrence of all types and manifestations of emphysema, which is consistent with the fact that smoking is an established cause of emphysema. Since loss of lung tissue, which characterises emphysema, represents a balance between injury and repair, it has been hypothesised that cigarette smoke contributes to the development of emphysema by inhibiting fibroblast action [13]. Fibrosis is produced by excessive production of collagen fibres by fibroblasts, and their conversion into tropocollagen [14]. Cigarette smoke extract has been shown to hinder the viability of human lung fibroblast-derived cells by inducing apoptosis in lower concentrations (10-25\%) and necrosis in higher concentrations (50-100\%) [15]. Cigarette smoke extract is also known to inhibit lung fibroblast proliferation and chemotaxis [13] and to inhibit fibroblast-mediated collagen gel contraction [16].

Increased bronchial wall thickness may be an early sign of chronic bronchitis and this was also positively associated with smoking in the studied population. Increased peribronchial fibrosis has been observed post mortem in chronic bronchitis and bronchial asthma [17].

Subpleural curvilinear lines are a nonspecific radiological sign. These may be seen in a variety of lung diseases, especially in asbestosis and scleroderma, but may also occur in normal patients [11]. In the present study, smoking was inversely related to the occurrence of curvilinear lines. Emphysema caused by tobacco smoke might hamper the detection of curvilinear lines, since emphysematous lungs may replace the fibrotic lung tissue. However, after adjustment with emphysema the findings from the study remained.

A significant inverse relation was observed between smoking and septal lines (interlobular septal thickenings). These are suggested to be associated with pneumoconioses, fibrosis and other aetiologies [11]. The inverse association of CT findings with smoking in the subgroup with exposure to $\leqslant 10$ pack-yrs also remained fairly constant after adjustment for emphysema. The deleterious effects of tobacco smoke on fibroblast function could theoretically explain the findings from this study on decreased fibrosis. However, BAUMGARTNER et al. [18] associated smoking with an increased risk of developing idiopathic pulmonary fibrosis. A slight positive association was detected between smoked pack-yrs and ground-glass opacities, a sign that could indicate respiratory bronchiolitis [19].

Researchers have tried to estimate the exposure to ETS by converting it to "cigarette equivalents" but the estimates have been variable depending on the biomarker used [20]. Based on cotinine measurements, nonsmokers are exposed to slightly more than one "cigarette equivalent" per day at the 
workplace, but this may apply only to the nicotine exposure. Simultaneously, nonsmokers passively exposed to tobacco smoke are receiving as much benzene as smokers would smoking six cigarettes, as much 4-aminobiphenyl as if smoking 17 cigarettes, and as much $N$-nitrosodimethylamine as a person who has smoked 75 cigarettes [20]. Models using data restricted to smokers with a low smoking rate have been used to estimate lung cancer risk related to exposure to ETS [21]. As the interviews undertaken did not include the history of ETS exposure, this study used a similar approach for the evaluation of pulmonary CT changes. The associations between relatively minor cumulative smoking and paraseptal emphysema, bronchial wall thickening and bronchiectasis indicate that even limited smoke exposure is a health risk. This finding may have relevance when the potential respiratory effects of ETS exposure are considered.

In conclusion smoking was related to several abnormal radiological signs in computed tomography and high-resolution computed tomography. These relations were found even among those with a relatively minor exposure of up to 10 pack-yrs, indicating that computed tomography can detect changes due to smoking at an early stage. Tobacco smoking promotes all forms of emphysema and bronchial wall thickening, while it seems to be associated with reduced computed tomography signs of fibrosis. Interpreters of chest computed tomography should be familiar with the findings related to smoking.

\section{Appendix 1: The 13 radiological signs assessed}

\begin{tabular}{|c|c|}
\hline Subpleural dependent opacity & $\begin{array}{l}\text { 0: no; } 1: \text { mild; } 2 \text { : moderate; } \\
\text { 3: severe }\end{array}$ \\
\hline Subpleural curvilinear opacity & $0:$ no; if yes, scale $1-5$ \\
\hline Subpleural septal lines & $0:$ no; if yes, scale $1-5$ \\
\hline $\begin{array}{l}\text { Parenchymal bands with a } \\
\text { length } 2-5 \mathrm{~cm}\end{array}$ & 0 : no; if yes, scale $1-5$ \\
\hline Subpleural nodules & 0 : no; if yes, scale $1-5$ \\
\hline Honeycombing & 0 : no; if yes, scale $1-5$ \\
\hline Ground-glass opacities & 0 : no; if yes, scale $1-5$ \\
\hline Centrilobular emphysema & 0 : no; if yes, scale $1-5$ \\
\hline Paraseptal emphysema & 0 : no; if yes, scale $1-5$ \\
\hline Panlobular emphysema & 0 : no; if yes, scale $1-5$ \\
\hline Bullae & 0 : no; if yes, scale $1-5$ \\
\hline Bronchial wall thickness & $\begin{array}{l}\text { 0: no; 1: mild; 2: moderate; } \\
\text { 3: severe }\end{array}$ \\
\hline Bronchiectasis & 0 : no; if yes, scale $1-3$ \\
\hline
\end{tabular}

The radiological signs with six categories $(0-5)$ were scored as follows:

0: normal finding

1: faint and few abnormalities, usually in a single slice

2: more distinct abnormalities in a single slice or abnormalities

in two slices

3: clear abnormalities in two to five slices

4: score between 3 and 5

5: abnormalities widely distributed in the whole lung, in all or most slices.

The radiological signs with four categories (0-3) were scored as follows:

0: normal

1: a single faint dependent opacity, a faintly thickened wall in one to two bronchi, or mildly dilated bronchi

2: a clear dependent opacity in one to three slices, several bronchi with thickened wall, or one to three saccular bronchiectasis

3: dependent opacities in almost all slices, several bronchi with thickened walls and usually filled with mucus, or bronchiectasis widely distributed in the lungs.

Acknowledgements. The authors would like to thank H. Lehtola for the patient interviews, A. Zitting for image scoring and T. Kaustia for the language revision. The Finnish Work Environment Fund and the Federation of Accident Insurance Institutions supported the original data collection.

\section{References}

1. Boyle P. Cancer, cigarette smoking and premature death in Europe: a review including the Recommendations of European Cancer Experts Consensus Meeting, Helsinki, October 1996. Lung Cancer 1997; 17: 1-60.

2. US Dept of Health and Human Services. Reducing the health consequences of smoking: 25 years of progress. A report of the Surgeon General. Dept of Health and Human Services Publication No. 89-8411. US Dept of Health and Human Services, Public Health Service, Centers for Disease Control, Center for Chronic Disease Prevention and Health Promotion, Office of Smoking and Health, 1989.

3. Remy-Jardin M, Remy J, Boulenquez C, Sobaszek A, Edme JL, Furon D. Morphologic effects of cigarette smoking on airways and pulmonary parenchyma in healthy adult volunteers: CT evaluation and correlation with pulmonary function tests. Radiology 1993; 186: 107-115.

4. Tiitola M, Kivisaari L, Huuskonen MS, et al. Computed tomography screening for lung cancer in asbestos-exposed workers. Lung Cancer 2002; 35: 17-22.

5. Huuskonen O, Kivisaari L, Zitting A, Taskinen K, Tossavainen A, Vehmas T. High resolution computed tomography classification of lung fibrosis in patients with asbestos-related disease. Scand J Work Environ Health 2001; 27: 106-112.

6. Erren TC, Jacobsen M, Piekarski C. Synergy between asbestos and smoking on lung cancer risks. Epidemiology 1999; 10: 405-411.

7. Kraus T, Raithel HJ, Lehnert G. Computer-assisted classification system for chest X-ray and computed tomography findings in occupational lung disease. Int Arch Occup Environ Health 1997; 69: 482-486.

8. Michel JL, Catilina P, Laubignat JF, Gabrillargues D. Are there criteria to allow the selection of patients exposed to asbestos which are relevant to thoracic computed tomography screening? J Radiol 1999; 80: 141-145.

9. Suganuma N, Kusaka Y, Hosoda Y, et al. The Japanese classification of computed tomography for pneumoconioses with standard films: comparison with the ILO international classification of radiographs for pneumoconioses. $J$ Occup Health 2001; 43: 24-31.

10. Tiitola M, Vehmas T, Tervahartiala $\mathrm{P}$, et al. Estimation or quantification of tumour volume? CT-study on irregular phantoms. Acta Radiol 2001; 42: 101-105.

11. Webb RW, Müller NL, Naidich DP. HRCT findings of lung disease. In: Webb RW, Müller NL, Naidich DP, eds. Highresolution CT of the lung. 2nd Edn. Philadelphia, LippincottRaven, 1996; pp. 41-108.

12. Mastora I, Remy-Jardin M, Sobaszek A, Boulenguez C, Remy J, Edme JL. Thin-section CT finding in 250 volunteers: assessment of the relationship of CT findings with smoking history and pulmonary function test results. Radiology 2001; 218: 695-702.

13. Nakamura Y, Romberger DJ, Tate L, et al. Cigarette smoke inhibits lung fibroblast proliferation and chemotaxis. Am J Respir Crit Care Med 1995; 151: 1497-1503.

14. Parker WR. Fundamentals of pathogenesis and pathology. 
In: Parker WR, ed. Occupational lung disorders. 2nd Edn. London, Butterworths, 1982; pp. 54-88.

15. Ishii $\mathrm{T}$, Matsuse $\mathrm{T}$, Igarashi $\mathrm{H}$, Masuda $\mathrm{M}$, Teramoto $\mathrm{S}$, Ouchi Y. Tobacco smoke reduces viability in human lung fibroblasts: protective effect of glutathione S-transferase P1. Am J Physiol Lung Cell Mol Physiol 2001; 280: L1189-L1195.

16. Carnevali S, Nakamura Y, Mio T, et al. Cigarette smoke extract inhibits fibroblast-mediated collagen gel contraction. Am J Physiol 1998; 274: L591-L598.

17. Haraguchi M, Shimura S, Shirato K. Morphometric analysis of bronchial cartilage in chronic obstructive pulmonary disease and bronchial asthma. Am J Respir Crit Care Med 1999; 159: 1005-1013.
18. Baumgartner KB, Samet JM, Stidley CA, Colby TV, Waldron JA. Cigarette smoking: a risk factor for idiopathic pulmonary fibrosis. Am J Respir Crit Care Med 1997; 155: 242-248.

19. Hartman TE, Tazelaar HD, Swensen SJ, Muller NL. Cigarette smoking: CT and pathologic findings of associated pulmonary diseases. Radiographics 1997; 17: 377-390.

20. Hammond SK, Sorensen G, Youngstrom R, Ockene JK. Occupational exposure to environmental tobacco smoke. JAMA 1995; 274: 956-960.

21. Lubin JH. Estimating lung cancer risk with exposure to environmental tobacco smoke. Environ Health Perspect 1999; 107: Suppl. 6, 879-883. 